\title{
RALEIO DE GEMAS FLORAIS PARA A REDUÇÃO DO ABORTAMENTO EM PEREIRA (Pyrus pyrifolia) NA REGIÃO DE PELOTAS-RS ${ }^{1}$
}

\author{
RENATO TREVISAN ${ }^{2}$, GERALDO CHAVARRIA², FLAVIO GILBERTO HERTER ${ }^{4}$ EMERSON DIAS GONÇALVES $^{2}$, \\ ALEXANDRE COUTO RODRIGUES ${ }^{2}$, VALTAIR VERÍSSIMO ${ }^{3}$, IVAN DOS SANTOS PEREIRA ${ }^{5}$
}

\begin{abstract}
RESUMO - No Brasil, a exploração comercial da cultura da pereira tem pouca expressão, devido à baixa produtividade das plantas, sendo o consumo interno abastecido pelas importações. A falta de adaptação das cultivares e o abortamento de gemas florais são os principais problemas para o seu desenvolvimento. Este trabalho teve como objetivo avaliar o efeito do raleio de gemas florais na redução do abortamento, nas cultivares asiáticas Nijisseiki e Shinseiki. As observações foram realizadas em três períodos: no início do inverno (junho), no início da primavera (setembro) e na primavera (novembro) de 2003. O experimento foi conduzido em blocos ao acaso, com três repetições, sendo o abortamento de gemas a variável avaliada. Embora o raleio de gemas não tenha diminuído os índices de abortamento nas cultivares, devem ser feitos novos estudos, podendo, desta forma, constituir-se numa prática cultural, para tentar reduzir o abortamento de gemas florais que se intensifica no inverno e início da primavera, em regiões onde o frio acumulado no inverno é insuficiente.
\end{abstract}

Termos para indexação: Adaptação, temperatura, pêra.

\section{BUD FLOWER THINNING ON THE REDUCTION OF ABORTION IN PEAR (Pyrus pyrifolia) IN PELOTAS REGION}

\begin{abstract}
The commercial exploration of the pear culture in Brazil has little expression, due to the low productivity of the plants, being the internal consumption supplied by imports. The lack of adaptation and flower bud abortion, are the main problems for the development of this crop. This work had the objective to evaluate the effect of flower buds thinning on the reduction of the abortion, in Asian cultivars Nijisseiki and Shinseiki. Flower abortion was evaluated at three different times: beginning of the winter (June), spring (September) and end of spring (November) during the year of 2003. The experiment was carried out in a randomized block design with three replicates. The parameter evaluated was the percentage of flower bud abortion. Although the bud thinning has not reduced the abortion indexes in the cultivars, new studies will must be done, being able to, constitute in a cultural practice, trying to reduce the bud floral abortion which intensifies in the winter and in the beginning of the spring, in areas where the chilling hours is insufficient.
\end{abstract}

Index terms: Adaptation, temperature, pear.

Dentre as frutas de clima temperado, a pêra é a terceira mais consumida no Brasil, sendo superada pela maçã e pelo pêssego. A falta de material genético e a deficiência de tecnologias de manejo, bem como o abortamento de gemas florais, são os principais problemas para o desenvolvimento da cultura, o que tem dificultado a produção de pêra nas condições do sul brasileiras, limitando a expansão do cultivo (Camelatto et al., 2000; Herter et al., 2001).

O abortamento é um fenômeno que ocorre no sul do Brasil (Nakasu \& Leite, 1992) e em outros países, como a Espanha, Bélgica e Nova Zelândia (Montesinos \& Vilardell, 1996). É caracterizado pela necrose dos primórdios das gemas florais destruindo-as parcial ou totalmente, e, dependendo da época e da cultivar, podem apresentar intensidades de 30 a 100\% de abortamento (Nakasu \& Leite, 1992).

Várias hipóteses têm sido formuladas para explicar esse fenômeno, dentre as quais, a insuficiência de horas frio $\left(\leq 7,2^{\circ} \mathrm{C}\right)$. Entretanto, Marodin et al. (1997) relatam que a falta de frio e as flutuações térmicas durante a dormência das plantas não devem ser tão somente as causas do abortamento. Para Gardin (2002), a diminuição de reservas nutricionais (carboidratos) nas gemas causa o abortamento. Hatting et al. (1989) descrevem que o fenômeno ocorre devido a doenças fúngicas nas gemas; desta forma, Berton \& Denardi (2003), ao aplicarem diferentes doses de aliette e calda bordalesa, não observaram efeito na redução do abortamento de gemas. Outros estudos foram e estão sendo realizados para melhor entender este fenômeno, dentre os quais, podas de outono e inverno (Mooney et al., 1992), desfolhamento total das plantas, redução de gemas floríferas (Herter et al., 2002) e controle químico (Berton \& Denardi, 2003). A eliminação de 50\% das gemas floríferas nas plantas, teoricamente, disponibiliza maior quantidade de reservas para as gemas, possibilitando melhor estrutura fisiológica para a gema florífera remanescente, evitando a queda, visto que o vigor e o desenvolvimento decorrem da quantidade de reservas (carboidratos) que recebem. Herter et al. (2002), ao eliminarem 50\% das gemas floríferas, obtiveram redução no percentual de abortamento (54\%) em relação à testemunha $(74,34 \%)$.

Tendo em vista a falta de respostas concretas sobre o abortamento de gemas florais em pereira, o presente trabalho teve como objetivo avaliar a influência do raleio de gemas floríferas na redução do abortamento em duas cultivares asiáticas, Nijisseiki e Shinseiki.

O experimento foi realizado no pomar da Embrapa Clima Temperado, em plantas de pereira asiática, cultivares Nijisseiki e Shinseiki, em junho de 2003. Para cada cultivar, foram selecionadas seis plantas, onde três receberam o tratamento raleio de gemas, e outras três, mantidas como controle. No tratamento raleio, foram removidas, aproximadamente, $50 \%$ das gemas floríferas das plantas, com auxílio de tesoura de poda. Após, selecionaram-se quatro ramos em cada planta, de cada cultivar, contando-se as gemas remanescentes após a realização do raleio. Nas plantas-testemunha, apenas realizou-se a contagem das gemas nos ramos de cada cultivar. A avaliação da percentagem de abortamento foi determinada pela contagem de gemas nas cultivares, após 30 dias da execução dos tratamentos. A contagem das gemas foi realizada em três períodos: início do inverno (23-07-2003), início da primavera (29-092003) e na primavera (05-11-2005).

Para a análise estatística, utilizou-se a média dos quatro ramos selecionados para cada tratamento e cultivar. O delineamento experimental utilizado foi em blocos ao acaso, com três repetições, utilizando o teste DMS a 5\% de probabilidade de erro. Os dados foram transformados em arc-sen $\sqrt{\mathrm{x} / 100}$, através do programa estatístico Sanest.

Os dados referentes às temperaturas e horas de frio $\leq 7,2^{\circ} \mathrm{C}$ no

\footnotetext{
(Trabalho 107/2004). Recebido: 17/09/2004. Aceito para publicação: 04/11/2005.

${ }^{2}$ Eng. Agr. Dr., RD/CNPq-Embrapa Clima Temperado. BR 392 Km 78, C.P.403. cep 96001-970, Pelotas, RS. Email: trevisan@cpact.embrapa.br; emersong@cpact.embrapa.br.

${ }^{3}$ Eng. Agr. Aluno de pós-graduação, FAEM/UFPel, C.P 354. Email: geraldochavarria@hotmail.com; Email: valtairverissimo@yahoo.com.br.

${ }^{4}$ Eng. Agr. Dr. Pesquisador Embrapa Clima Temperado C.P. 403, Pelotas, RS. Email: herter@cpact.emnbrapa.br.

${ }^{5}$ Aluno de graduação, bolsista CNPq, FAEM/UFPel. C.P. 354. Email: ivan@cpact.embrapa.br.
} 


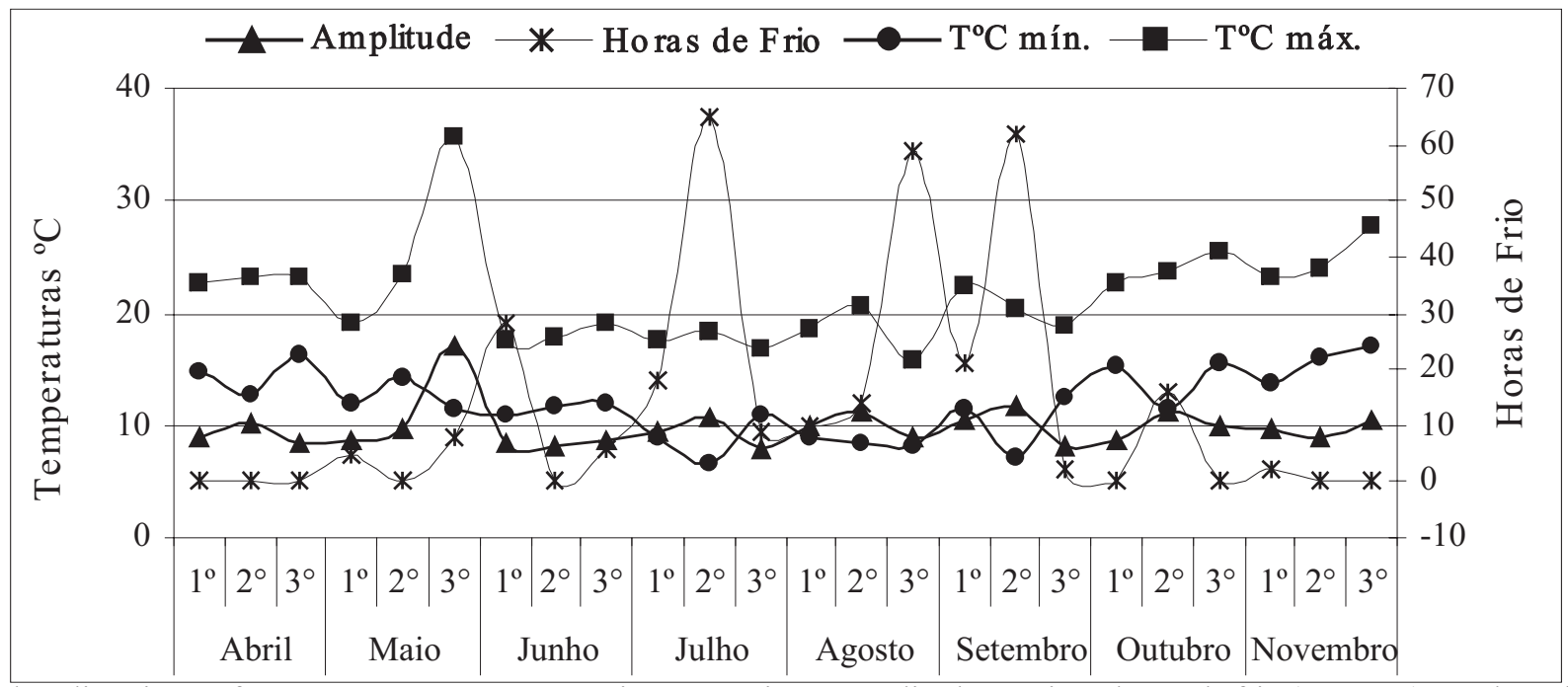

FIGURA 1 - Dados climáticos referentes às temperaturas máximas e mínimas, amplitude térmica e horas de frio $\left(\leq 7,2^{\circ} \mathrm{C}\right)$ nos decênios dos meses de abril a novembro de 2003. Embrapa Clima Temperado, Pelotas-RS, 2005.

período estão representados na Figura 1 e foram obtidos no Laboratório de Agroclimatologia da Embrapa Clima Temperado.

$\mathrm{O}$ raleio de gemas não reduziu o abortamento; entretanto, houve interação significativa entre as cultivares e época de avaliação (Tabela 1). Herter et al. (2001) encontraram diferenças significativas quando realizaram a eliminação de $50 \%$ de gemas na cultivar Nijisseiki, o que não foi encontrado neste trabalho. A causa determinante do aumento do índice de abortamento no período que antecede a floração, é de difícil interpretação, mas o abortamento poderá estar relacionado com o esgotamento das reservas nutricionais da gema, importantes no desenvolvimento floral final.

TABELA 1 - Percentagem de gemas floríferas abortadas nas cultivares Nijisseiki e Shinseiki, nos três períodos de avaliação.

\begin{tabular}{lcc}
\hline Período & Nijisseiki & Shinseiki \\
\cline { 2 - 3 } & \multicolumn{2}{c}{$\%$ gemas abortadas } \\
\hline Início do inverno & $53,1 \mathrm{aA}$ & $65 \mathrm{a} \mathrm{B}$ \\
Início da primavera & $60,3 \mathrm{a} \mathrm{A}$ & $70,2 \mathrm{a} \mathrm{B}$ \\
Primavera & $91,1 \mathrm{~b} \mathrm{~B}$ & $85,8 \mathrm{~b} \mathrm{~A}$ \\
\hline Média geral & & 29,2 \\
CV (\%) & & 30,00 \\
\hline
\end{tabular}

Médias seguidas da mesma letra, minúscula na coluna e maiúscula na linha, não diferem entre si, pelo teste DMS, a 5\% de probabilidade.

Neste trabalho, verificou-se que o abortamento, já no início do inverno, estava elevado, em torno de $50 \%$. O aumento progressivo do fenômeno também foi observado por Gardin (2002), porém no início da primavera. Na Tabela 1, observa-se que houve diferenças significativas entre os períodos de avaliação, sendo que, na última avaliação, os índices foram os mais elevados. Observa-se, também, que as cultivares diferiram significativamente dentre cada período de avaliação. A cultivar Shinseiki, nos dois primeiros períodos, obteve maiores percentuais de gemas abortadas do que a Nijisseiki. Entretanto, ao final da primavera, obteve $86 \%$ de abortamento; já a Nijisseiki, $91 \%$. Esses índices são extremamente elevados e comprometem a produção.

Uma das causas deste alto percentual de abortamento pode estar relacionada com as flutuações térmicas ocorridas no período da avaliação deste estudo. A insuficiência de frio e a flutuação térmica durante o inverno também são citadas como fatores causais do abortamento floral nas condições do Sul do Brasil (Herter et al., 1994). Na Figura 1, verifica-se que a flutuação da temperatura no início de agosto elevou-se, reduzindo-se ao final do mesmo período, o mesmo acontecendo em setembro. Para Hough (1990), essa flutuação da temperatura ocasiona o abortamento das gemas floríferas, o que foi constatado neste estudo. -Fato também relatado por Camelatto (1992), que, se ocorrer um aumento de calor no final do inverno, início de primavera, pode aumentar o abortamento em conseqüência do aumento da taxa respiratória, pois consome grande parte das reservas destinadas aos órgãos internos das gemas e ramos.

Outro fator que pode ter influenciado nos elevados índices de abortamento, está relacionado ao acúmulo de horas de frio. No período deste estudo, o acúmulo de frio $\left(\mathrm{d}^{\prime} 7,2^{\circ} \mathrm{C}\right)$ foi de 315 horas (Figura 1). Desta forma, o acúmulo de frio não foi suficiente, pois a cultivar Nijisseiki requer aproximadamente 800 horas, e a Shinseiki, 550 horas de frio. Faoro (2001) cita que, dependendo da exigência de frio de cada cultivar, quanto maior o número de horas de frio, mais intensa é a floração, reduzindo assim a taxa de abortamento das gemas.

Neste contexto, embora o raleio de gemas não tenha diminuído os índices de abortamento nas cultivares estudadas, devem ser feitos novos estudos relacionados ao assunto, podendo, desta forma, constituir numa prática cultural para tentar reduzir o abortamento de gemas florais em pereira, em regiões onde o frio acumulado no inverno é insuficiente.

\section{REFERÊNCIAS}

BERTON, O.; DENARDI, F. Efeito do aliette e da calda bordalesa no controle do abortamento de gemas floríferas em pereira. Agropecuária Catarinense, Florianópolis, v.16, n.1, p.41-44, 2003.

CAMELATTO, D. The relationship between fruit set of apple and carbohidrate content of bark and flower cluster base tissues. 1992. 198f. Dissertation (PhD) - State University, East Lensing, 1992.

CAMELATTO, D.; NACHTIGALL, G.R.;ARRUDA, J.J.P.; HERTER, F.G. Efeitos de flutuações de temperaturas, horas de frio hibernal e reguladores de crescimento no abortamento de gemas florais de pereiras. Revista Brasileira de Fruticultura, Jaboticabal, SP. v.22, n.1, P.111-117, 2000.

FAORO, I.D. Morfologia e fisiologia. In: EPAGRI. Nashi: a pêra japonesa. Florianópolis: Epagri. 2001, v.1, p.67-94.

GARDIN, J.P.P. Abortamento de gemas florais e níveis de carboidratos em gemas e ramos de pereira, cultivar Nijisseiki, no outono e inverno. 32f. Dissertação (Mestrado) - Universidade Federal de Pelotas, Pelotas, 2002.

HATTING, M.J.; ROOS, I.M.M.; MANSVELT, E.L. Infection and systemic invasion of deciduous fruit trees by Pseudomonas syringae in South Africa. Plant Disease, St. Paul, v.73, n.10, p.784-789, 1989.

HERTER, F.G.; VERÍSSIMO, V.; CAMELATTO, D.; GARDIN, J.P.; TREVISAN, R. Abortamento de gemas florais de pereira no Brasil. In: PERSPECTIVAS DA FRUTICULTURA DE CLIMA TEMPERADO NA REGIÃO SUBTROPICAL: ESTRATÉGIAS E TECNOLOGIAS PARA A SUSTENTABILIDADE DA FRUTICULTURA DE BAIXO IMPACTO AMBIENTAL, 2001, 
Florianópolis. Anais... p.106.

HERTER, F.G.; CAMELATTO, D.; TREVISAN, R.; VERÍSSIMO, V.; GARDIN, J.P.; The effects of spur pruning and defoliation in the autumn on the flower bud abortion of pear tree cv. Nijisseiki in Pelotas, RS, Brazil. In: INTERNATIONAL SYMPOSIUM ONASIAN PEARS COMMEMRATING THE $100^{\text {th }}$ ANNIVERSARY OF NIJISSEIKY PEAR, 2002, Belgium, 2002. Proceedings... v.1,p.369373

HERTER, F.G.; BASSOLS M.C.; NAKASU, B.H. Época de abortamento de gemas florais em Pereira e sua relação com a temperatura ambiente, em Pelotas-RS. Revista Brasileira de Fruticultura, Cruz das Almas, v.16, n.1, p.3008-314, 1994.

HOUGH, L.F. Introduzione di specie temperate nelle regioni sub-tropicali dell'America Latina. Rivista di Frutticoltura e di Ortofloricoltura, Bolognha, v.67, n.1, p.23-31, 1990.
MOONEY, P.; KLINAC, D.; KILLEN, W. et al. Time of pruning effects on "budjump" of nashi. Orchadist of New Zealand, Kerikeri, v.65, n.5, p.19-21, 1992

MARODIN, G.A.B.; KOLLER, O.C.; BERGAMASCHI, H.; CAMELATTO, D. Abortamento de gemas florais de pereira Packham's Triumph na região Sul do Brasil. In: REUNIÃO DE INTEGRAÇÃO PESQUISA X ENSINO DO CPACT, 1997, Pelotas. Anais... p.46.

MONTESINOS, E.; VILARDELL, P. La necrosis de yemas de flor em el peral. Uma efermedad compeja y difícil control. Fruticultura Professional, Barcelona, n.78, p.88-94, 1996.

NAKASU, B.H.; LEITE, D.L. Pirus 9 - Seleção de pereira para região Sul do Brasil. HortiSul, Pelotas, v.2, n.3, p. 19-20, 1992. 